\title{
Selective Coexpression of Insulin Receptor-related Receptor (IRR) and TRK in NGF-Sensitive Neurons
}

\author{
R. R. Reinhardt, ${ }^{1}$ E. Chin, ${ }^{1}$ B. Zhang, ${ }^{2}$ R. A. Roth, ${ }^{2}$ and C. A. Bondy ${ }^{1}$ \\ 'Developmental Endocrinology Branch, $\mathrm{NICHD}, \mathrm{NIH}$, Bethesda, Maryland 20892, and 2Department of Pharmacology, \\ Stanford University, Stanford, California 94305
}

\begin{abstract}
The insulin receptor-related receptor (IRR) has recently been identified as a member of the insulin receptor tyrosine kinase family; however, its endogenous ligand and biological function are still unknown. In contrast to the very widespread pattern of expression of the homologous insulin and IGF-I receptors, IRR demonstrates a very restricted cellular distribution. Using in situ hybridization and immunohistochemistry, we now show that the expression of this receptor is selectively concentrated in a subset of neurons where its appearance is closely associated with that of the NGF receptor TRK. IRR and TRK demonstrate synchronized patterns of coexpression in neural crest-derived sensory and sympathetic neurons and in non-neural crest basal forebrain and striatal neurons. Both appear early in the embryonic development of dorsal root and trigeminal neurons and somewhat later, near the time of birth, in sympathetic neurons. Expression of both IRR and TRK appears perinatally in basal forebrain neurons, reaching maximal levels about postnatal day 20 . This association is highly selective, since TRK mRNA is not detected anywhere in the developing nervous system in the absence of coordinate IRR expression, and the same is true for IRR expression with respect to TRK. In the adult rat, the majority of TRK-positive sensory neurons still express IRR mRNA, and coexpression in sympathetic and forebrain neurons continues without evidence of diminution. These findings are consistent with a functional linkage of the IRR and TRK receptors in NGF-sensitive neurons.

[Key words: neural crest, tyrosine kinase, basal forebrain, sensory neuron, neurotrophin, embryonic development]
\end{abstract}

The insulin receptor-related receptor (IRR) is a member of a tyrosine kinase receptor family that includes the insulin and IGF-I receptors (Yarden and Ullrich, 1988; Shier and Watt, 1989). These three receptors share a common structure consisting of an extracellular, cysteine-rich $\alpha$ domain that determines ligand specificity and a $\beta$ membrane-spanning domain that contains kinase activity in its cytoplasmic portion (Ullrich et al., 1986; Steele-Perkins et al., 1988; Zhang and Roth, 1992). The $\alpha$ and $\beta$ sequences are derived from a single pro-receptor molecule that is cleaved during processing, after which the two

\footnotetext{
Received Nov. 29, 1993; revised Feb. 3, 1994; accepted Feb. 8, 1994.

We are grateful to Ricardo Dreyfus for expert photomicrography and to Dr. Eric Shooter for providing NGF, BDNF, and neurotrophins 3 and 4 . This work was in part supported by NIH Grant DK 456521 to R.A.R.

Correspondence should be addressed to C. A. Bondy, NIH, Building 10, Room 10N262, Bethesda, MD 20892.

Copyright (C) 1994 Society for Neuroscience $0270-6474 / 94 / 144674-10 \$ 05.00 / 0$
}

domains remain connected by intramolecular disulfide bonds. Intermolecular disulfide bonds join pro-receptor molecules into membrane-spanning dimers that constitute the active receptor. The insulin and IGF-I receptors consist of homologous dimers, but recent data suggest that functional hybrid receptors composed of insulin and IGF-I hemireceptors are expressed in a variety of tissues, although their physiological role is as yet undefined (Moxham et al., 1989: Soos et al., 1993). The IRR was identified by means of low-stringency screening of genomic libraries using a human insulin receptor clone (Shier and Watt, 1989). IRR's predicted amino acid sequence is as closely related to the insulin receptor as is the IGF-I receptor, with a particularly high degree of identity in $\beta$ domain regions involved with signal transduction, although IRR is predicted to have a shorter carboxyl terminal than the insulin and IGF-I receptors.

Neither insulin nor any insulin-related peptides have been found to activate IRR, at least when the receptor is expressed in transfected CHO cells as a chimera consisting of the extracellular, presumed ligand-binding domain of the IRR coupled to the insulin receptor tyrosine kinase (Zhang and Roth, 1992). In contrast to the very widespread expression patterns of the insulin and IGF-I receptors, IRR demonstrates a highly restricted distribution. In the developing rat embryo, IRR mRNA is concentrated in neural crest-derived sensory and sympathetic neurons (Reinhardt et al.. 1993), which are classically considered to be nerve growth factor (NGF) dependent for survival. In fact, the pattern of IRR gene expression during embryonic development appeared identical to that of the proto-oncogene product TRK (Martin-Zanca et al., 1990), which has recently been identified as an NGF receptor (reviewed in Chao, 1992). This receptor was initially identified in the form of an oncogene where a somatic genetic rearrangement resulted in disruption of the normal sequence by a portion of a tropomyosin molecule, resulting in constitutive activation (Martin-Zanca et al., 1986). A relationship between the proto-oncogene product and NGF was deduced after in situ hybridization showed that TRK mRNA was concentrated in NGF-sensitive sensory ganglia during embryonic development (Martin-Zanca et al., 1990), followed by evidence that NGF binds and triggers TRK autophosphorylation (Kaplan et al., 1991; Klein et al., 1991a). Homology-based cloning techniques have demonstrated a number of TRK-related receptors that interact with NGF-related neurotrophins with different degrees of specificity (reviewed in Chao, 1992).

The present study used in situ hybridization and immunohistochemistry of serial sections to compare TRK and IRR expression in the nervous system during development and maturity. We have found that these two receptors demonstrate temporally coordinated, selective colocalization in NGF-sen- 
sitive populations, including both neural crest-derived and nonneural crest-derived neurons.

\section{Materials and Methods}

Tissue preparation. Timed-pregnant Sprague-Dawley rats (Taconic Farms, Germantown, NY) were decapitated after carbon dioxide anesthesia and fetuses were removed by hysterotomy in accord with a protocol approved by the NICHD Animal Use Committee. Gestational age was calculated by taking the day of appearance of the mother's vaginal plug as E0 and was confirmed for each embryo by correlation of crown-rump length and developmental landmarks with the atlas of Hebel and Stromberg (1986). E12-E18 embryos were fixed in Bouin's solution and infiltrated with paraffin. Sections of $8 \mu \mathrm{m}$ thickness were cut, mounted on poly-L-lysine-coated slides, and dried for several hours at $50^{\circ} \mathrm{C}$ on a slide warmer. E20 cmbryos and postnatal tissue were frozen over dry ice and serial tissue sections $(8-10 \mu \mathrm{m})$ were cut at $-15^{\circ} \mathrm{C}$, thaw mounted onto poly-L-lysine slides, and stored at $-70^{\circ} \mathrm{C}$ until use. Analysis of gene expression in the rat brain was accomplished by the screening of serial sagittal sections from E16, E20, P1, P5, P12, P20, and $\mathrm{P} 40$ brains. All brain regions where hybrids were detected, from forebrain to cerebellum, were further analyzed in serial coronal sections. Tissue sections from a human lumbar parasympathetic ganglion were obtained from the NIH Clinical Pathology Department.

Preparation of RNA probes and in situ hybridization. The rat exon 3 and human exon 2 IRR clones used in this study both encode extracellular portions of the receptor and do not hybridize to insulin or IGF-I receptor mRNAs (Zhang and Roth, 1991). They were subcloned into Bluescript KS (Stratagene, Torrence, CA) so that linearization with HindIII and use of T7 polymerase generated antisense transcripts of 400 or 620 base pairs for the rat and human probes, respectively. Linearization with EcoRI and T3 polymerase was used to generate sense probes. The mouse TRK clone (pDM 97), corresponding to 464 bases from the extracellular domain, was kindly supplied by Dr. Luis Parada, Frederick, MD. This was subcloned into pGEM- $72 \mathrm{~F}(+)$ such that linearization with SacI and use of T7 polymerase yielded antisense transcripts. ${ }^{35}$ S-double-labeled cRNA probes were synthesized and in situ hybridization performed as previously described (Bondy et al., 1990). After hybridization and stringency washes, slides were air dried, apposed to Hyperfilm-beta Max (Amersham, Arlington Heights, IL) for 5-7 d, and then dipped in Kodak NTB2 nuclear emulsion, stored with desiccant at $4^{\circ} \mathrm{C}$ for $14-21 \mathrm{~d}$, developed, and stained with Mayer's hematoxylin and eosin for microscopic evaluation.

Immunocytochemistry. The polyclonal anti-IRR antibody was produced in rabbits by injection of a bacterially produced fusion protein encoded by exon 2 of human IRR fused to glutathione transferase. The antisera were affinity purified on an affinity column containing this fusion protein. The monoclonal anti-TRK antibody, which reacts with both TRK and TRK-B, was obtained from Austral biologicals (San Ramon, CA). Fluorescein-streptavidin was acquired from Amersham (Arlington Heights, IL), and other reagents were purchased from Vector (Burlingame, CA). Immunocytochemistry was performed on frozen tissue sections that were fixed in $4 \%$ paraformaldehyde in $100 \mathrm{~mm}$ phosphate buffer $(\mathrm{pH} \mathrm{7.1)}$ for $30 \mathrm{~min}$ at RT. The sections were rinsed twice with wash buffer $(0.2 \%$ BSA; $100 \mathrm{~mm}$ glycerol; $0.05 \%$ thimerosal in $1 \times$ PBS, pH 7.4) for $30 \mathrm{sec}$. The tissue was incubated for $1 \mathrm{hr}$ with $15 \%$ normal goat serum (IRR) and $15 \%$ normal horse serum (TRK) at RT. The tissue was then incubated overnight at $4^{\circ} \mathrm{C}$ with the primary antibody in 5\% normal serum and rinsed four times for $30 \mathrm{sec}$ with wash buffer. The tissue was incubated for $3 \mathrm{hr}$ with biotinated anti-rabbit (IRR) and biotinated anti-mouse (TRK) in 5\% normal serum at RT, washed four times, and then incubated $3 \mathrm{hr}$ with fluorescein-streptavidin in 5\% normal animal serum at RT. The sections were lastly rinsed four times with wash buffer and mounted with Vectashield. Controls were performed as above with the omission of the primary antibody.

\section{Results}

Neural crest-derived neurons

TRK mRNA was detected in dorsal root ganglia (DRG) at E12, slightly before IRR mRNA was detected (Fig. 1 $B, C$ ). IRR mRNA was detected in DRGs at E13 (not shown), and by E16 both TRK and IRR mRNAs were abundant in DRGs and in the jugular and trigeminal ganglia (TGG; Figs. $1 D-F, 2$ ). These ganglia consist of very numerous, tightly packed, small cells at this early stage, so it was not possible, at the level of resolution allowed by the ${ }^{35} \mathrm{~S}$-label nuclear track, to determine whether TRK and IRR were localized in a subpopulation of neurons (Fig. 2). Note that both these mRNAs were expressed in neural crest-derived sensory (superior and jugular) ganglia associated with cranial nerves 9 and 10 , but not in the placode-derived acoustic/vestibular or nodose ganglia (Figs. 1, 2).

IRR and TRK mRNAs remained abundant in dorsal root and trigeminal ganglia at E20, by which time clear morphological differentiation made it possible to identify a subpopulation of IRR/TRK-positive neurons (Figs. 3, 4). IRR/TRK-positive cells averaged $\sim 15 \mu$ in diameter and represented $\sim 50 \%$ of the total ganglion neuronal population in TGG and $\sim 70 \%$ in DRGs at E20. (Hybrid-negative cells containing $<4$ grains were scored in serial sections through the midportion of two lumbar DRG and two trigeminal ganglia.) IRR/TRK-positive neurons were larger in size $(\sim 30 \mu)$ in adult trigeminal and dorsal root ganglia (Figs. 3, 4). The large cell size and low cell density of the mature sensory ganglia allowed us to compare IRR and TRK expression in individual cells using serial sections. Sets of serial, $8 \mu$ sections (IRR:TRK:IRR) for each ganglion were photographed at $400 \times$ and cells were scored on $4 \times 5$ inch contact prints. Nonspecific signal as determined by hybridization with the sense IRR probe was $2.8 \pm 1.9$ grains/neuron (mean $\pm \mathrm{SD}$ for 50 cells). Antisense-hybridized neurons with seven or more silver grains were scored as positive. Analysis of 30 IRR-positive TGG neurons where the same cell could be clearly identified in serial TRKhybridized sections revealed that 30 of 30 cells also contained TRK mRNA. The same type of analysis performed on TRKpositive TGG neurons revealed that 28 of 30 also expressed IRR (Fig. 3E,F). Furthermore, although the cell density and total cell number were significantly reduced in adult TGG, approximately the same percentage $(\sim 50 \%)$ of neurons were IRR: TRK positive in the adult and in the E20 TGG. The analysis of adult DRGs by the same methods showed that while $100 \%$ of IRR-positive DRG neurons also expressed TRK mRNA, only 23 of 30 or approximately $75 \%$ of TRK-positive neurons also contained detectable IRR mRNA (Fig. $4 A, B$ ).

IRR/TRK expression appeared later during development in the autonomic nervous system than in neural crest-derived sensory ganglia. Neither was detected at E16, but both mRNAs were detected in virtually all neurons of the sympathetic and parasympathetic ganglia in E20 embryos (Fig. $1 D-I$ ) and in the superior cervical ganglion of adults (Fig. 5). Parasympathetic ganglia were not evaluated in the postnatal rat, but TRK and IRR mRNAs (not shown) and immunoreactivity were colocalized in neurons from an adult human perirenal parasympathetic ganglion (Fig. $4 C, D$ ). The anti-TRK antibody might cross-react with TRK-B or $-C$, but TRK-B mRNA was not detected and only a few cells were TRK-C positive in this ganglion (not shown), suggesting that the antibody is detecting primarily TRK in this site. The anti-IRR antibody is specific for the human IRR carboxy-terminal region and does not recognize the insulin or IGF-I receptors (Zhang and Roth, unpublished observations). This antibody did not detect IRR in rat tissues, which was not unexpected since the carboxy tail demonstrates significant interspecies variation (Shier and Watt, 1989).

\section{Central nervous system}

Little IRR or TRK mRNA was detected in the brain before birth (Fig. 1), but both increased in the CNS during postnatal 


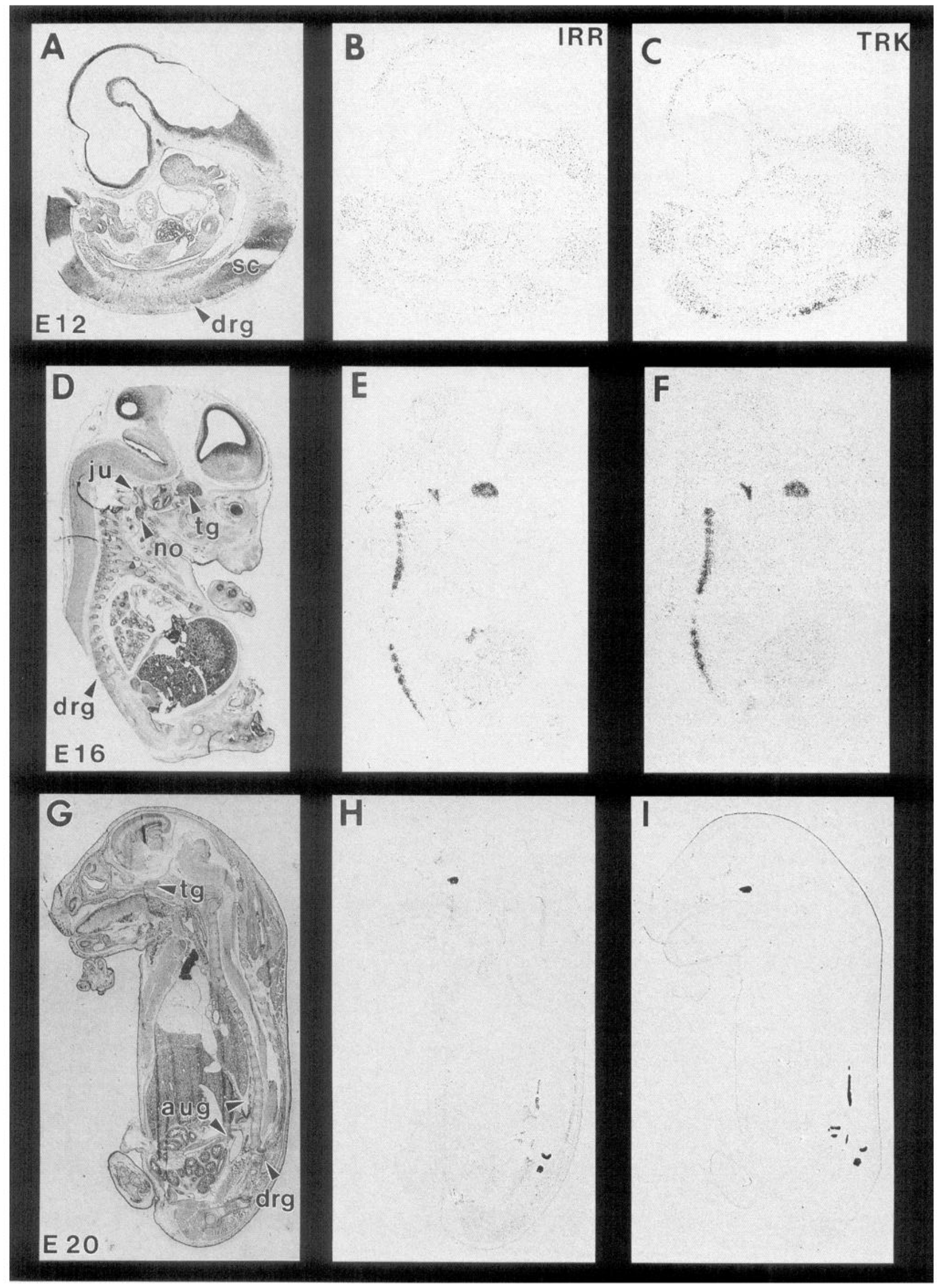




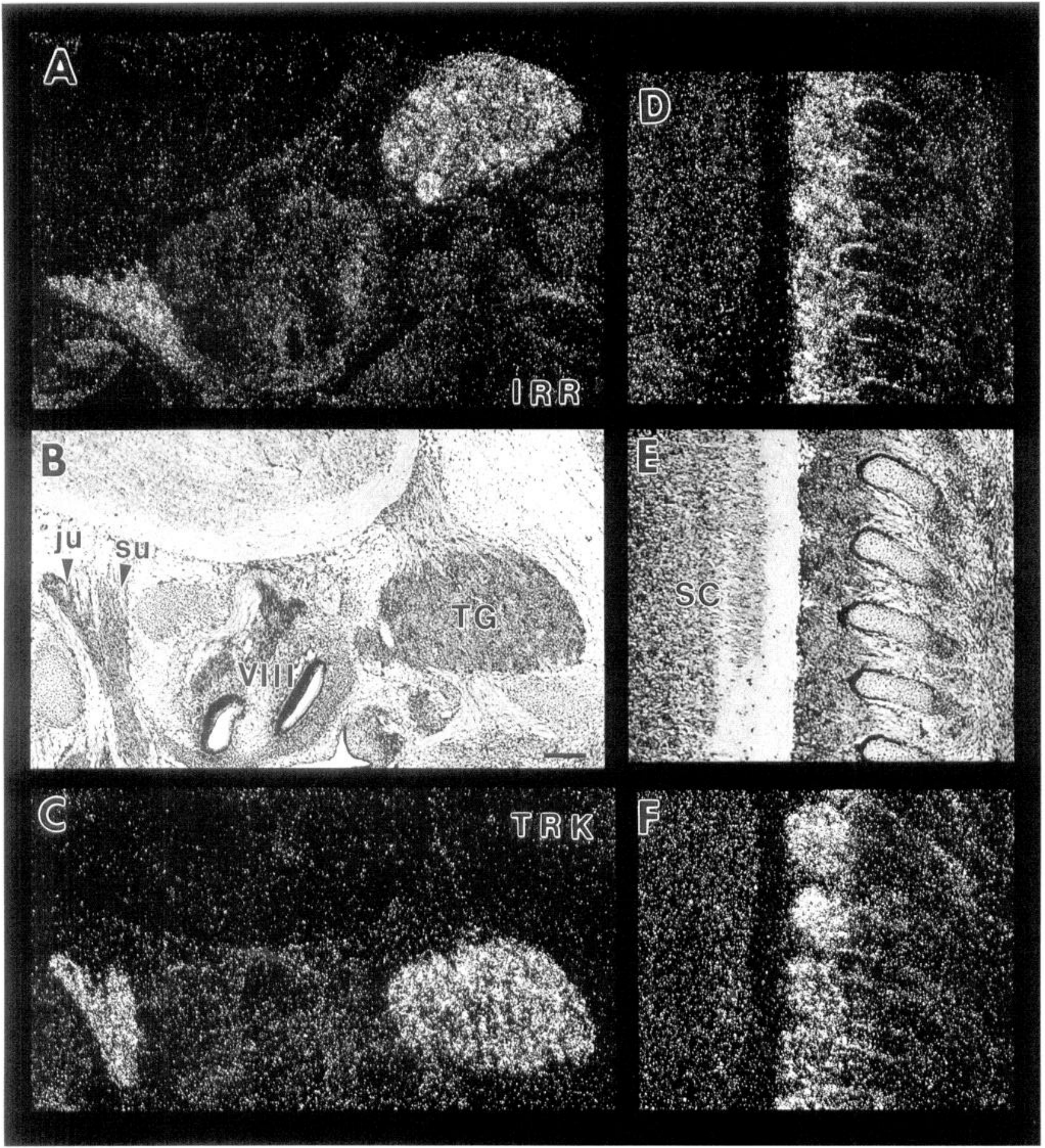

Figure 2. IRR and TRK mRNAs in sensory ganglia at El6. These are micrographs from the embryos shown in Figure 1. $A$ and $D$, Dark-field illuminations of IRR hybridization in cranial and dorsal root ganglia. $B$ and $E$, Bright-field illuminations of a sequential section that was hybridized for TRK, shown in dark-field below $(C$ and $F$ ). The dark-field photo in $A$ is framed at a slightly different angle from that used in $B$ and $C$. ju, jugular ganglion; $S C$, spinal cord; $s u$, superior ganglion; $T G$, trigeminal ganglion; $V I I I$, cochlear-vestibular ganglia and nerve. Scale bar, $100 \mu \mathrm{m}$.

Figure 1. Comparison of IRR $(B, E$, and $H)$ and TRK $(C, F$, and $I)$ gene expression in serial sagittal sections during embryonic development. Hematoxylin and eosin-stained sagittal sections are followed in each row by film autoradiographs of IRR and TRK in situ hybridization at E12 $(A-C)$. E16 $(D-F)$, and E20 $(G-I)$. aug, autonomic ganglia, including the thoracic sympathetic chain and parasympathetic ganglia associated with bowel and mesentery; $\mathrm{drg}$, dorsal root ganglia; $j u$, jugular ganglia; no, nodose ganglia; $s c$, spinal cord; $t g$, trigeminal ganglion. 


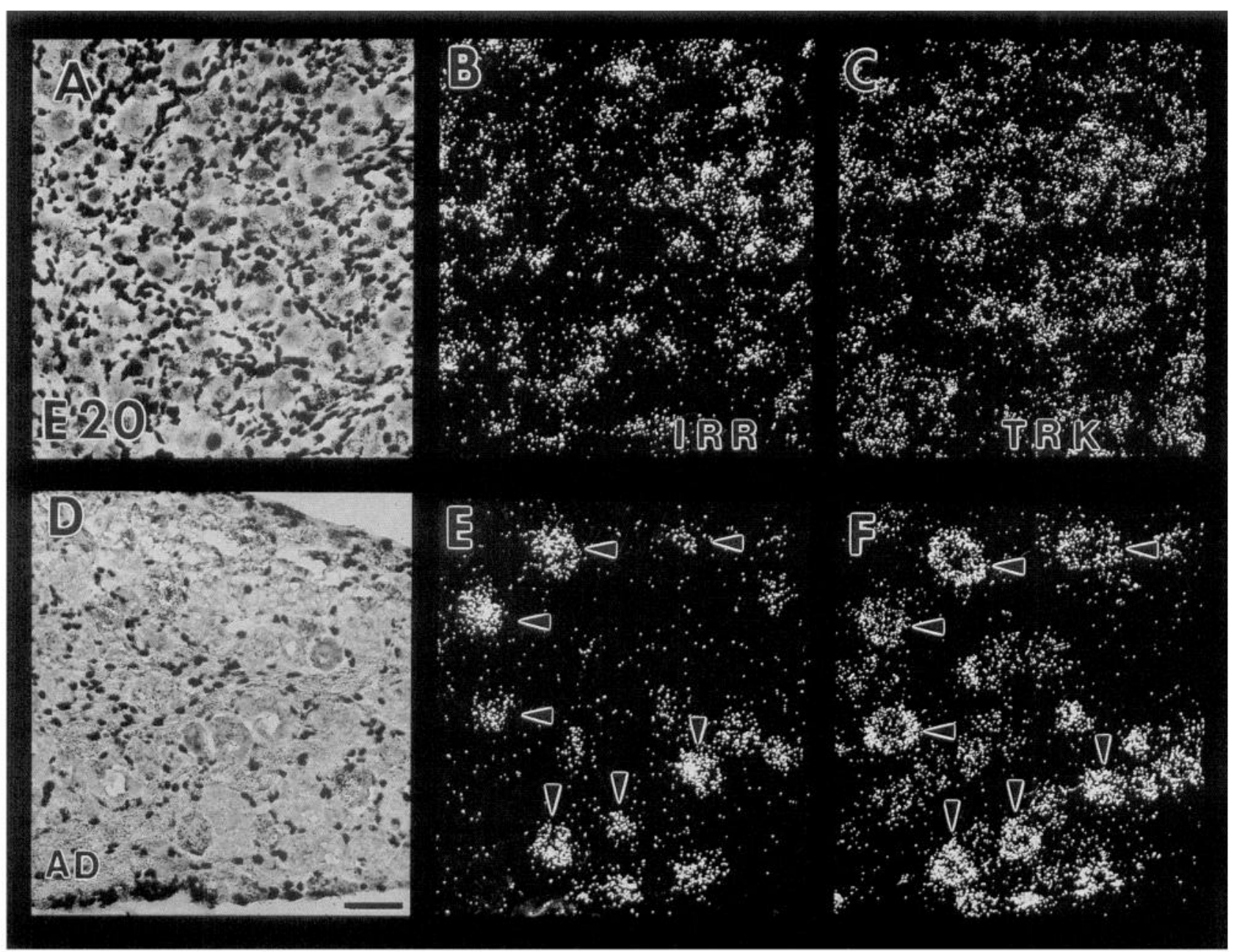

Figure 3. Comparison of IRR $(B$ and $E)$ and TRK $(C$ and $F)$ gene expression in trigeminal ganglia at E20 $(A-C)$ and in the adult $(D-F)$. The cells are too small at E20 to allow demonstration of colocalization in serial sections, but in the larger, adult neurons IRR/TRK coexpression is obvious (arrowheads, $E$ and $F$ ). Notice, however, that the IRR signal is more central while TRK signal is more peripheral in each neuronal soma. Scale bar, $40 \mu \mathrm{m}$.

development. Low-level expression of TRK and IRR mRNAs was detected in basal forebrain and striatal neurons at E20, and increased, in terms of both cell number and individual cell intensity, until P20 and continued thereafter without evidence of diminution (Fig. 6). In the forebrain and striatum as in the autonomic nervous system, IRR/TRK coexpression appeared to be virtually $100 \%$. Analysis of serial thin section sandwiches (IRR:TRK:IRR:TRK. . .) through the forebrain (Fig. 6) and the superior cervical ganglion (Fig. 5) revealed that every IRR mRNA-positive cell was also TRK hybrid positive. IRR:TRK coexpression was also detected in magnocellular neurons of several brainstem nuclei beginning perinatally and increasing until P20 and stable thereafter, at least until P40. TRK expression was not detected in any other brain sites. IRR mRNA, however, was detected in Purkinje cells from P20 in the absence of any detectable TRK expression in these cells (Fig. 7).

\section{Discussion}

This study has shown that mRNAs encoding IRR, an orphan receptor belonging to the insulin receptor family, and TRK, the founding member of a neurotrophin receptor family, are coexpressed in distinct NGF-sensitive subpopulations of neurons.
It is likely that coexpression of these mRNAs results in coexpression of the receptors, since IRR and TRK immunoreactivities were colocalized in neurons in a human parasympathetic ganglion. The potential functional significance of neuronal IRR/ TRK colocalization is supported by the fact that their expression is temporally closely coordinated. IRR expression appears shortly after TRK early in the development of neural crest-derived dorsal root and trigeminal ganglia. Both transcripts are detected somewhat later in the embryonic development of the autonomic nervous system and both demonstrate onset of expression late in the development of non-neural crest-derived basal forebrain and caudate neurons.

The present data on TRK gene expression correlate well with previous observations describing TRK mRNA in mouse neural crest-derived sensory ganglia from E11 to E17 (Martin-Zanca et al., 1990), in adult rat basal forebrain and caudate putamen (Holtzman et al., 1992; Ringstedt et al., 1993) and sensory and sympathetic ganglia (Ernfors et al., 1992; Verge et al., 1992). To our knowledge, however, the present study presents the first longitudinal analysis to compare TRK gene expression through pre- and postnatal development in all these systems and to show that the ontogeny of TRK and IRR expression in these different 


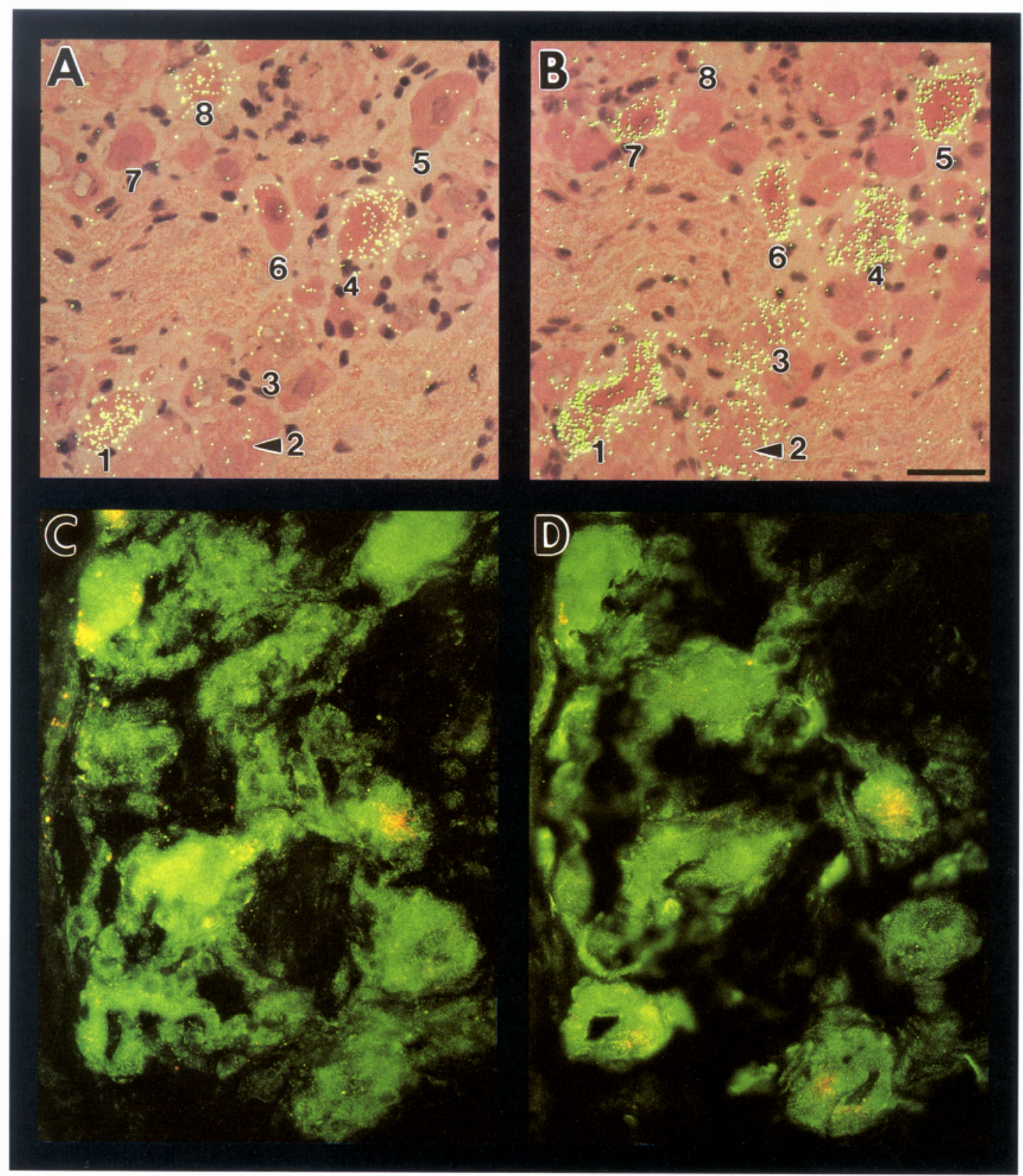

Figure 4. Comparison of IRR $(A)$ and TRK $(B)$ gene expression in dorsal root sensory neurons of the adult rat and IRR $(C)$ and TRK $(D)$ immunoreactivity in human parasympathetic neurons. Cells are labeled with numbers placed directly beneath them in $A$ and $B$, except where indicated with an arrowhead. Cells $I$ and 4 demonstrate abundant hybridization grains for both IRR and TRK. Exposed silver grains appear green in this double-exposure micrograph in which a green filter is used for a dark-field exposure that is superimposed upon a color bright field. Cells 2 , 3,5 , and 6 contain abundant TRK signal but few IRR hybrids. Cell 7 , while very positive for TRK, contains no detectable IRR mRNA. Cell 8 contains abundant IRR signal, but cell 8 for TRK is out of the plane of section. Scale bar: $25 \mu \mathrm{m}$ for $A$ and $B, 12 \mu \mathrm{m}$ for $C$ and $D$.

systems corresponds to the order of their developmental acquisition of NGF sensitivity (reviewed in Barde, 1989). Specifically, neural crest-derived sensory neurons that are dependent on NGF for survival during embryonic development demonstrate TRK and IRR gene expression early in development, while sympathetic neurons, which appear most sensitive to NGF perinatally, demonstrate onset of receptor gene expression later in gestation. Finally, non-neural crest-derived basal forebrain neurons, which appear insensitive to NGF during embryonic development, demonstrate maximal IRR/TRK several weeks after birth. These TRK-expressing forebrain neurons demonstrate NGF sensitivity in the adult (Holtzman et al., 1992).
The only site in the nervous system where TRK expression was detected in the absence of IRR was in a few neurons in adult DRG and TGG. It appears, however, that this may be a result of a developmental reduction in IRR expression in these neurons, since IRR appears to be expressed in all TRK-positive DRG and TGG cells at E20. Thus, wherever TRK expression is seen in the nervous system, IRR is also present, with the exception of some sensory neurons where IRR was originally expressed but appears to have been downregulated during the course of development. IRR was detected in the absence of TRK in the mature (P20) Purkinje cell. A previous study, however, has shown that TRK-B is selectively localized in mature Pur- 


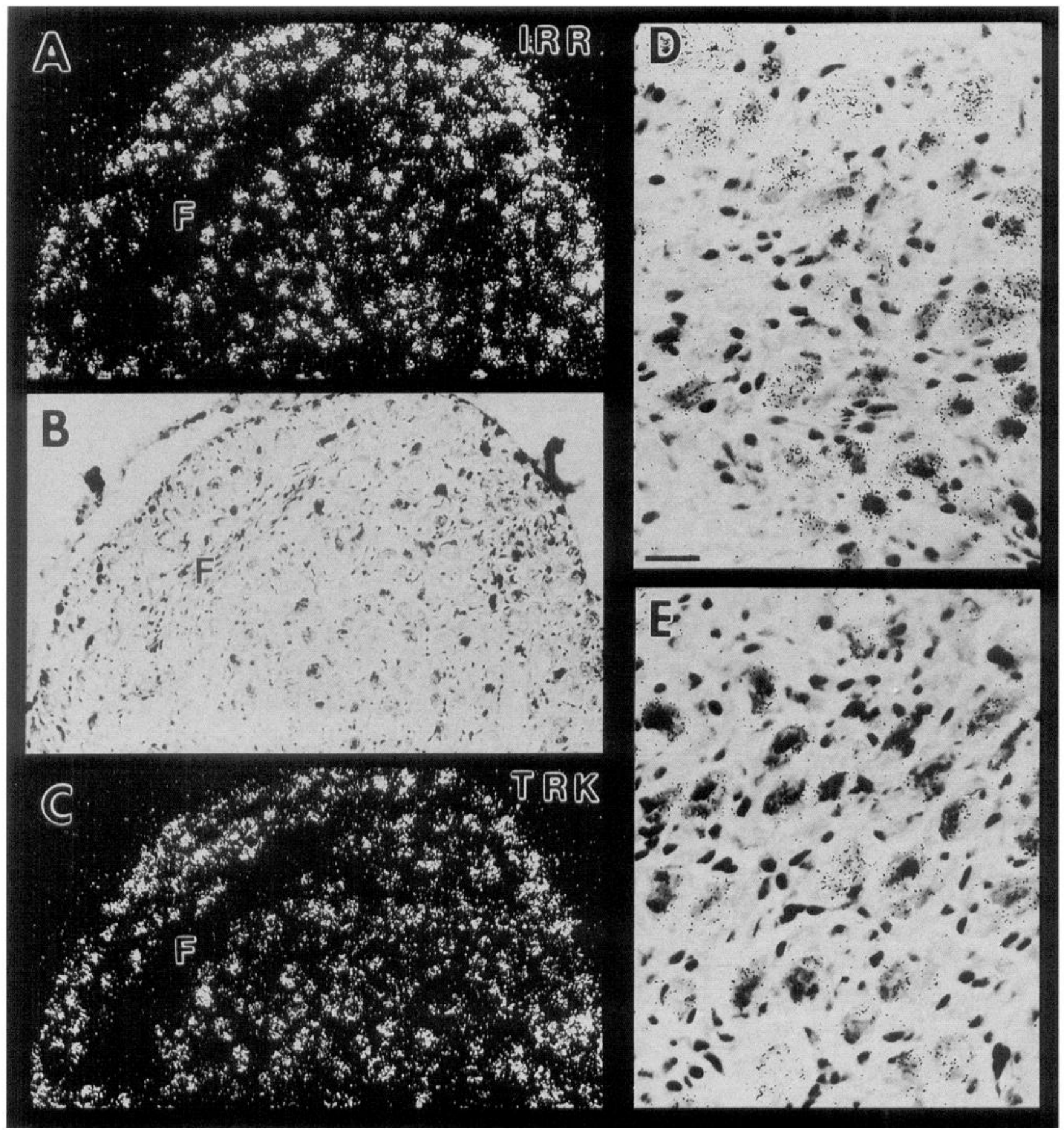

Figure 5. IRR $(A$ and $D)$ and TRK $(C$ and $E)$ mRNAs are colocalized in virtually all neurons in the adult superior cervical ganglion. $F$, fiber bundle. Scale bar: $40 \mu \mathrm{m}$ for $A-C$; and $20 \mu \mathrm{m}$ for $D$ and $E$.

kinje cells (Klein et al., 1990), suggesting an association between IRR and another member of the TRK tyrosine kinase receptor family in this setting. These findings suggest that there is a functional relationship between TRK or TRK-related receptors and IRR expression in the nervous system. We have previously shown that in addition to the nervous system, IRR is focally localized in a subset of renal distal tubule epithelial cells (Reinhardt et al., 1993). TRK or TRK-B mRNAs have not been detected in these cells (R. R. Reinhardt, E. Chin, B. Zhang, R.
A. Roth, and C. A. Bondy, unpublished observations); however, coexpression with other known (or not yet described) TRK family members has not been excluded.

It is not clear, at present, whether TRK acts independently to mediate the full biological response to NGF. When expressed in non-neuronal cells, TRK is capable of binding NGF and participating in signal transduction, but some evidence suggests that another factor in addition to TRK may be involved in generating high-affinity NGF binding (reviewed in Chao, 1992). 


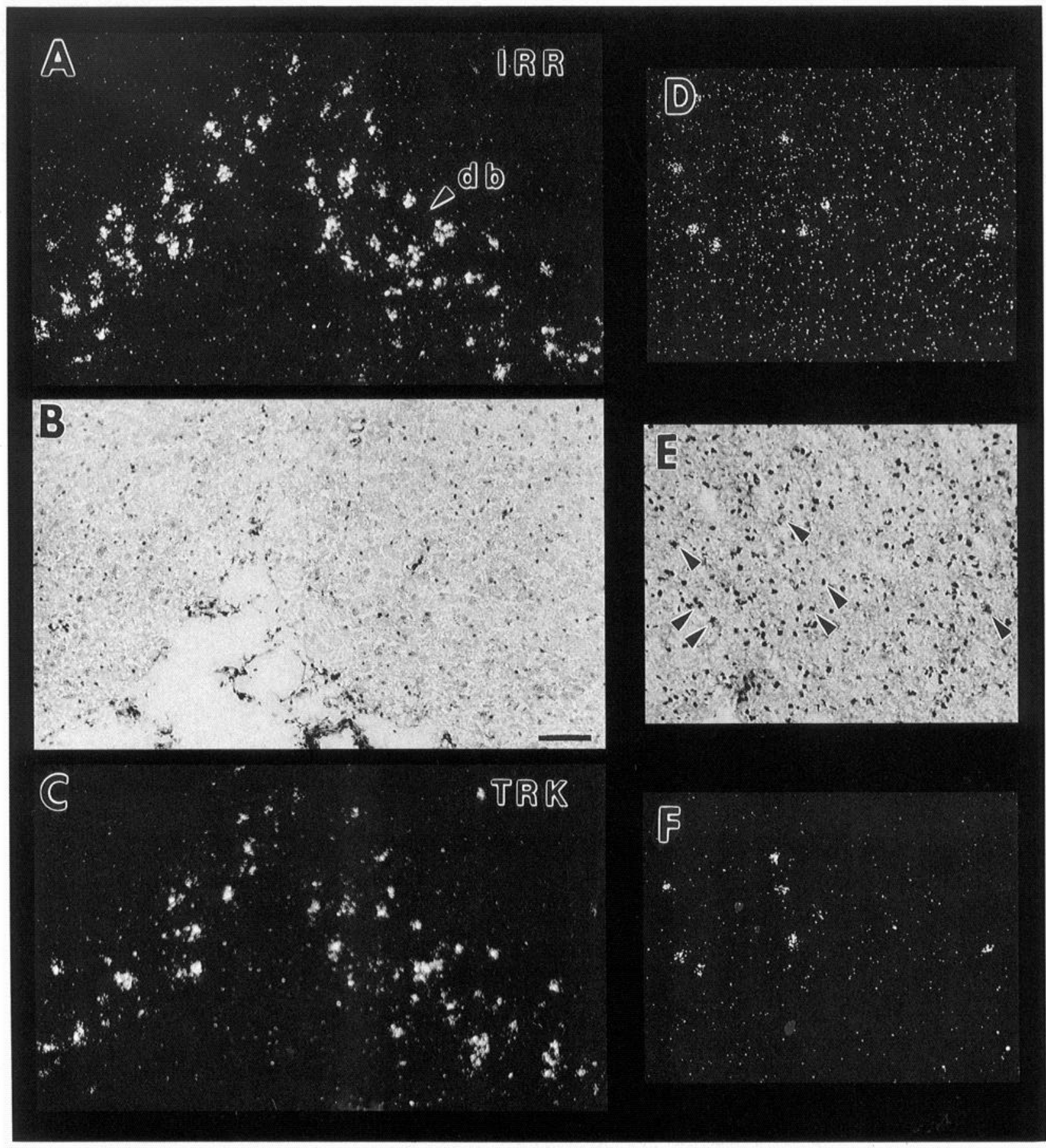

Figure 6. IRR $(A$ and $D)$ and TRK $(C$ and $F)$ mRNAs in basal forebrain $(A-C)$ and caudate $(D-F)$ neurons in the adult rat brain. $d b$, diagonal band nuclei. Arrowheads in $E$ point out the IRR/TRK-positive cells. Scale bar, $80 \mu \mathrm{m}$.

Furthermore, the biological effects mediated by transfected TRK in non-neuronal cells, such as the stimulation of proliferation in fibroblasts (Cordon-Cardo et al., 1991), are quite different from those of native TRK in neurons. Thus, other elements, in addition to TRK, are thought to be involved in determining NGF's effects in neurons. One obvious candidate is the p75 NGF receptor, which also binds NGF but appears to lack signal transduction capacity (reviewed in Chao, 1992). While there is extensive overlap in TRK and p75 NGF receptor expression, the latter is also widely expressed in non-neuronal tissues (re- viewed in Bothwell, 1991) where TRK is not found, and is not detected in some TRK-positive, NGF-sensitive neuron populations, such as the cholinergic neurons of the caudate putamen (Verge et al., 1992). In contrast, the correlation between TRK and IRR expression is much tighter, with IRR being selectively expressed in all TRK-positive populations, including the caudate neurons. This compelling spatiotemporal linkage in expression suggests that IRR may be involved with TRK in shaping the survival or differentiation of these specific classes of neurons. 


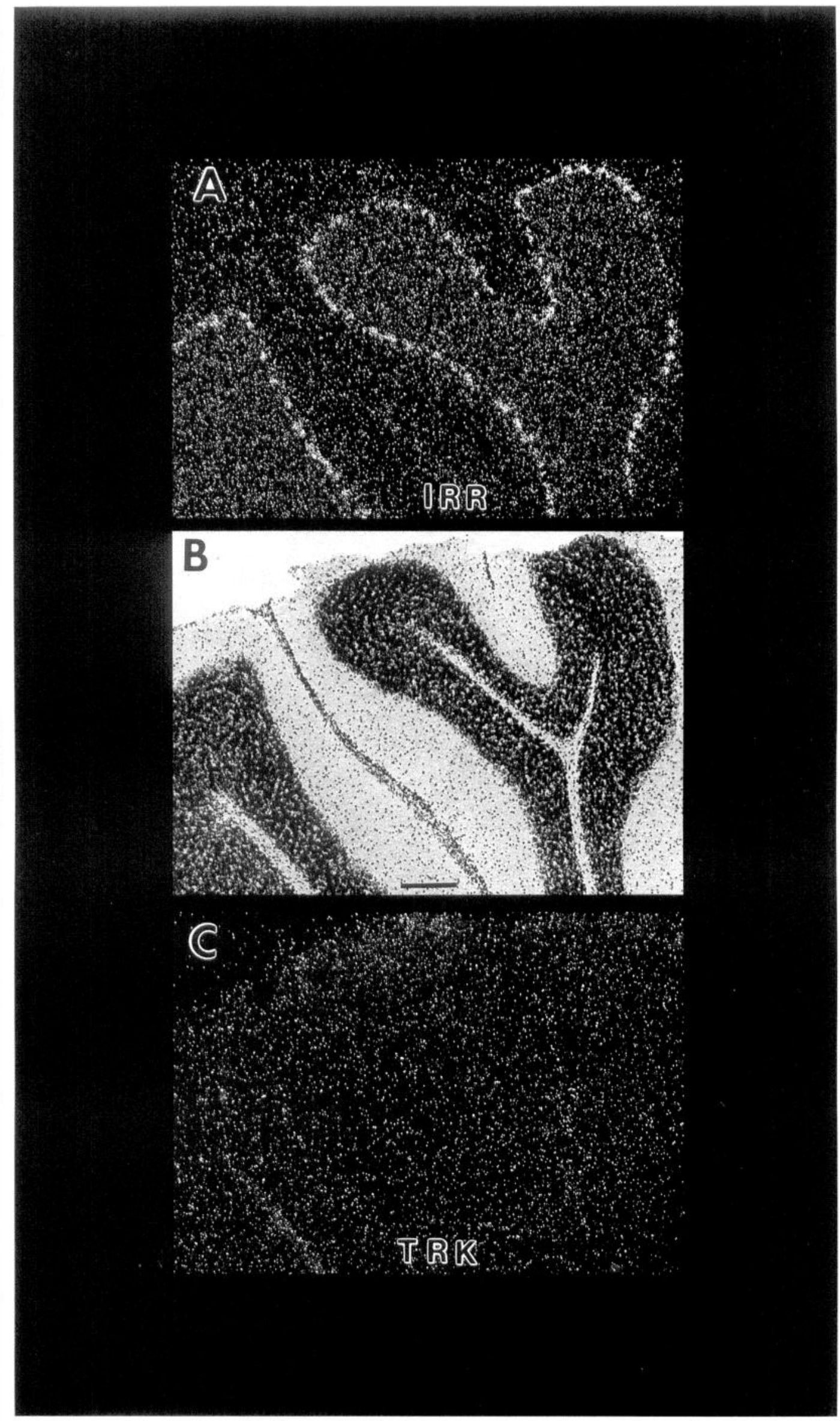

Figure 7. IRR but not TRK mRNA is localized in mature Purkinje cells. Scale bar, $100 \mu \mathrm{m}$. 
Even less is currently known about IRR's physical or functional characteristics in its normal cellular environment. This receptor has been investigated in the form of a chimeric transfectant in $\mathrm{CHO}$ cells, where the extracellular IRR domain has been fused to the insulin receptor cytoplasmic kinase (Zhang and Roth, 1991, 1992). This molecule does not bind or undergo phosphorylation in response to insulin or any known insulinrelated peptides (Zhang and Roth, 1992), or to NGF, BDNF, or neurotrophins 3 or 4 (K. Seto and R. Roth, unpublished observations). When the chimera is reversed, such that the IRR cytoplasmic domain is linked to the insulin receptor extracellular domain, insulin binding results in autophosphorylation and phosphorylation of the same substrates, including IRS-1, that are associated with the insulin and IGF-I receptors (Zhang and Roth, 1992). These results indicate that IRR activates the same signal transduction pathways as the insulin and IGF-I receptors, although it does not bind insulin or IGF-I, at least in the transfected form expressed in $\mathrm{CHO}$ cells.

The striking pattern of TRK and IRR coexpression seen in the developing and mature nervous system suggests that there is a functional linkage between these two membrane proteins, the nature of which is a matter of speculation at the present time. Both IRR and TRK belong to families of receptors that are active as dimers; heterodimerization within the family has been described for insulin receptors. It is not yet clear whether this may also occur with TRK family receptors. One possibility that should be considered is that IRR and TRK might be physically associated in the plasma membrane. In combination, these two proteins might specify a unique cellular address capable of binding ligands from the insulin or neurotrophin families in a manner not detected when the receptors are expressed singly. It is possible, although not considered likely, that IRR and TRK may form heterodimers. since there is significant homology between the insulin and TRK receptor families (Chao, 1992). In fact, the structural similarity is closest between IRR and TRK, since IRR has a relatively short carboxy tail (Shier and Watt, 1989). Alternatively, and perhaps more likely, the association between IRR and TRK may be strictly functional, with an unknown IRR ligand and NGF simultaneously or sequentially activating combinatorial signal transduction sequences by binding to their individual receptors. Further studies will be necessary to elucidate the relationships between the IRR and TRK receptors when coexpressed in neurons.

\section{References}

Barde Y-A (1989) Trophic factors and neuronal survival. Neuron 2:1525-1534.

Bondy CA (1991) Transient IGF-I gene expression during the maturation of functionally-related central projection neurons. J Neurosci 11:3442-3455.

Bondy CA, Chin E (1991) IGF-I mRNA localization in trigeminal and sympathetic target zones during rat development. In: Molecular biology and physiology of insulin and IGFs (Raizada M, LeRoith D, eds), pp 431-437. New York: Plenum.

Bondy CA, Werner H, Roberts C, LeRoith D (1990) Cellular pattern of insulin-like growth factor-I and type-I IGF receptor gene expression in early organogenesis; comparison with IGF-II gene expression. Mol Endocrinol 4:1386-1398.

Bothwell M (1991) Tissue localization of nerve growth factor and nerve growth factor receptors. Curr Top Microbiol Immunol 165:5570.

Chao MV (1992) Neurotrophin receptors: a window into neuronal differentiation. Neuron 9:583-593.

Cordon-Cardo C, Tapley P, Jing S, Nanduri V, O'Rourke E, Lamballe F, Kovary K, Klein K, Jones KR, Reichardt LF, Barbacid M (1991) The trk tyrosine protein kinase mediates the mitogenic properties of nerve growth factor and neurotrophin-3. Cell 66:173-183.

Ernfors P, Merlio JP, Persson H (1992) Cells expressing mRNA for neurotrophins and their receptors during embryonic rat development. Eur J Neurosci 4:1140-1158.

Hebel R, Stromberg MW (1986) Anatomy and embryology of the laboratory rat. Worthsee, Germany: Biomed Verlag.

Klein R, Martin-Zanca D, Barbacid M, Parada L (1990) Expression of the tyrosine kinase receptor gene trkB is confined to the murine embryonic and adult nervous system. Development 109:845-850.

Klein R, Jing S, Nanduri V, O'Rourke E, Barbacid M (1991a) The trk proto-oncogene encodes a receptor for nerve growth factor. Cell 65:189-197

Klein R, Nanduri V, Jing S, Lamballe F, Tapley P, Bryant S, CordonCardn C, Jones KR, Reichardt I.F, Barbacid M (1991b) The trkB tyrosine protein kinase is a receptor for neurotrophin-3 and brainderived neurotrophic factor. Cell 66:395-403.

Martin-Zanca D, Oskam R, Mitra G, Copeland T, Barbacid M (1989) Molecular and biochemical characterization of the human trk protooncogene. Mol Cell Biol 9:24-33.

Martin-Zanca D, Barbacid M, Parada LF (1990) Expression of the trk proto-oncogene is restricted to the sensory and spinal ganglia of neural crest origin in the mouse development. Genes Dev 4:683-694.

Martin-Zanca D, Hughs SH, Barbacid M (1986) A human oncogene formed by the fusion of truncated tropomyosin and protein tyrosine kinase sequences. Nature 319:743-748.

Moxham C, Duronio V, Jacobs S (1989) Insulin-like growth factor I receptor beta subunit heterogeneity. J Biol Chem 264:13238-13244.

Reinhardt RR, Chin E, Zhang B, Roth RA, Bondy CA (1993) Insulin receptor-related receptor $\mathrm{mRNA}$ is focally expressed in sensory neurons and renal distal tubule. Endocrinology 133:3-10.

Ringstedt T, Lagerkrantz H, Persson H (1993) Expression of members of the trk family in the developing postnatal rat brain. Dev Brain Res $72: 119-131$

Shier P, Watt VM (1989) Primary structure of a putative receptor for a ligand of the insulin family. J Biol Chem 264:14605-14608.

Steele-Perkins G, Turner J, Edman JC, Hari J, Pierce SB, Stover C, Rutter WJ, Roth RA (1988) Expression and characterization of a functional human insulin-like growth factor I receptor. J Biol Chem 263:11486-11492.

Soos M, Field C, Siddle K (1993) Purified hybrid insulin/insulin-like growth factor-I receptors bind IGF-I, but not insulin, with high affinity. Biochem J 290:419-426.

Ullrich A, Gray A, Tam AW, Yang-Feng T, Tsubokawa M, Collins C, Hanzel W, Le Bon T, Kathuria S, Chen E, Jacobs S, Francke U, Ramachandran J, Fujita-Yamaguchi Y (1986) Insulin-like growth factor I receptor primary structure: comparison with insulin receptor suggests structural determinants that define functional specificity. EMBO J 5:2503-2512.

Verge VMK, Merlio JP, Grondin J, Ernfors P, Persson H, Riopelle RJ, Hokfelt T, Richardson PM (1992) Colocalization of NGF binding sites, trk mRNA, and low-affinity NGF receptor mRNA in primary sensory neurons: responses to injury and infusion of NGF. J Neurosci 12:4011-4022.

Yarden Y, Ullrich A (1988) Growth factor receptor tyrosine kinases. Annu Rev Biochem 57:443-478.

Zhang B, Roth RA (1991) Binding properties of chimeric insulin receptors containing the cysteine-rich domain of either the insulin-like growth factor-I receptor or the insulin receptor-related receptor. Biochemistry 30:5113-5117.

Zhang B, Roth RA (1992) The insulin receptor-related receptor. Tissue expression, ligand binding specificity, and signaling capabilities. J Biol Chem 267:18320-18328. 